\title{
Heterogeneous neurodevelopmental disorders in children with Kawasaki disease: what is new today?
}

\author{
Chien-Heng Lin ${ }^{1,2}$, Wei-De Lin ${ }^{3}$, I-Ching Chou, ${ }^{4,5}$, Inn-Chi Lee ${ }^{6}$ and Syuan-Yu Hong ${ }^{4^{*}}$ (D)
}

\begin{abstract}
Background: Kawasaki disease (KD) is a common vasculitis of childhood in East Asia. The complications of KD ascribed to long-term cardiovascular sequelae are considerably diverse. Although studies have investigated neurodevelopmental problems following KD in the past few decades, they have reported inconsistent conclusions. This study investigated potential epilepsy and associated neurodevelopmental disorders (NDDs) following KD in Taiwanese children.
\end{abstract}

Methods: We retrospectively analyzed the data of children aged $<18$ years with clinically diagnosed KD from January 1, 2005, to December 31, 2015. These patients were followed up to estimate the prevalence of epilepsy and associated NDDs in comparison with the prevalence in general pediatric population in Taiwan and worldwide.

Results: A total of 612 patients with an average age of 1.6 years were included. The prevalence of associated NDDs was $16.8 \%(n=103 / 612)$ in the study group, which consisted of epilepsy, intellectual disability (ID), autism spectrum disorders, Tourette syndrome (TS), attention deficit hyperactivity disorder, (ADHD), and others. Moreover, children with KD had a higher prevalence of epilepsy and TS in both Taiwan and worldwide (epilepsy: $2.61 \%$ in the KD group vs $0.33 \%$ in Taiwan and $0.05-0.8 \%$ in worldwide, $p<0.05$; TS: $2.77 \%$ in the KD group vs $0.56 \%$ in Taiwan and $0.3-1 \%$ in worldwide, $p<0.05$ ). The prevalence of ID, ADHD, and developmental language disorders was not significantly different between our study patients and those in Taiwan or worldwide.

Conclusions: Results revealed a higher prevalence rate of NDDs, especially epilepsy and TS, in Taiwanese children with KD than in the general pediatric population in Taiwan. However, these NDDs could be heterogeneous. Children diagnosed with KD were followed up because they had a higher risk of heterogeneous NDDs.

Keywords: Kawasaki disease, Neurodevelopmental disorders, Children, Epilepsy, Tourette syndrome

\section{Background}

Kawasaki disease (KD), also known as mucocutaneous lymph node syndrome, is a common vasculitis of childhood, particularly in East Asia. The complications of KD, probably ascribed to long-term cardiovascular sequelae, are considerably diverse [1]. However, in addition to cardiac complications [2], noncardiac complications may affect children with KD [3, 4]. In KD, medium-sized muscular arteries, rather than small vessels, are most commonly affected. Hence, complications relevant to organs

\footnotetext{
* Correspondence: dazingdog@hotmail.com

${ }^{4}$ Division of Pediatrics Neurology, China Medical Univeristy Children's

Hospital, Taichung, Taiwan

Full list of author information is available at the end of the article
}

outside the heart but abundant in such vascular beds have been observed over the past few decades [3], including urinary or renal disease [5], gastrointestinal abnormalities, and those related to the central nervous system $[6,7]$.

Among complications of KD, few studies have investigated those related to the central nervous system, but they have reported inconsistent conclusions regarding their long-term neurological problems [7-9]. Little is known regarding the correlation between neurodevelopmental disorders (NDDs) and KD and their different prevalence rates.

We conducted this retrospective observational study between January 1, 2005, and December 31, 2015, and followed up until December 31, 2018 to investigate the 
occurrence of potential epilepsy and associated NDDs following KD in Taiwanese children. The findings of this study can provide extensive insights into KD-related NDDs.

\section{Methods}

\section{Data sources and study population}

In this retrospective cohort study, we analyzed patients aged $<18$ years with clinically suspected KD. The following preliminary inclusion criteria were based upon diagnostic criteria for KD between January 1, 2005, and December 31, 2015 [10].

The presence of fever lasting at least 5 days without any other explanation combined with at least four of the five following criteria:

(1) Bilateral bulbar conjunctival injection

(2) Oral mucous membrane changes, including injected or fissured lips, injected pharynx, or strawberry tongue

(3) Peripheral extremity changes, including erythema of the palms or soles, edema of the hands or feet (acute phase), and periungual desquamation (convalescent phase)

(4) Polymorphous rash

(5) Cervical lymphadenopathy (at least 1 lymph node > $1.5 \mathrm{~cm}$ in diameter).

A comprehensive medical record review was strictly enforced to exclude children who had epilepsy, neurologic, metabolic, autoimmune (other than KD), or any other congenital disorders before the onset of $\mathrm{KD}$. Other exclusion criteria were as follows:

(1) Loss of contact with a patient during the follow-up period

(2) Patients who developed NDDs or epilepsy with documented etiology or followed by a causative event; for example, central nervous system infections, copy number variations, or single gene mutations, which are related to epilepsy and NDDs.

(3) Patients who were born relatively preterm $(<32$ weeks)

(4) Patients who had a perinatal history of hypoxic ischemic encephalopathy or birth asphyxia and congenital infection.

(5) Patients who had a history of traumatic brain injury.

(6) Maternal medication use during pregnancy; for example, heavy smoking, drinking, and drug abuse.

The last patient was enrolled in December 2015. All patients included in the study were followed up from baseline until the end of follow-up (December 31, 2018), withdrawal from the insurance program, or death. We followed up patients by reviewing their medical records and contacting their families through telephone or email quarterly since the beginning of 2016. Once NDD was suspected, we contacted the children returning to our pediatric neurology clinic for a comprehensive assessment. We compiled statistics and proceeded with the analysis to observe the prevalence of associated NDDs in our study children during 2018. A flowchart of the study is shown in Fig. 1.

Instruments used for assessing children and adolescents with suspected intellectual disability (ID) were Bayley Scales of Infant and Toddler Development, Third Edition (for young children aged $<2$ years) and Wechsler Preschool and Primary Scale of Intelligence (for children aged 2 years 6 months to 7 years 7 months). Epilepsy (our outcome of interest) was defined as the occurrence of two unprovoked seizures more than $24 \mathrm{~h}$ apart, which was diagnosed by a pediatric neurologist. Patients who met relevant diagnostic criteria in the Fourth and Fifth Editions of Diagnostic and Statistical Manual of Mental Disorders were diagnosed with autism spectrum disorder (ASD) and attention deficit hyperactivity disorder (ADHD); Tourette syndrome (TS) was diagnosed on the basis of the Tourette Syndrome Classification Study Group criteria [11], a guideline for our children's neurology clinic, and TS was diagnosed by a pediatric psychiatrist or a pediatric neurologist in the inpatient or outpatient setting of China Medical University Children's Hospital between January 1, 2005, and December 31, 2018.

\section{Statistical analysis}

Although we did not set up a control group for children with $\mathrm{KD}$, we conducted a thorough article review as well as to compare the incidence rates of various NDDs in the Taiwan population and other populations worldwide with those in our study population. Moreover, we randomly select 23,699 children (age 0-18) from National Health Insurance Research Database (NHIRD) during 2015-2016 as a reference to compare the prevalence of various NDDs with our results. The study protocol was approved by the Ethics Review Board of the China Medical University Ethics Committee. All statistical analyses were performed using PASW Statistics version 18.0 software (SPSS Inc., Chicago, IL, USA). In addition, for all executed statistical analyses, we considered two-tailed $p<0.05$ to indicate statistical significance.

\section{Results}

\section{Data analysis}

Between January 1, 2005, and December 31, 2015, 612 children diagnosed with KD were enrolled in this study. Participants' demographic factors are presented in 


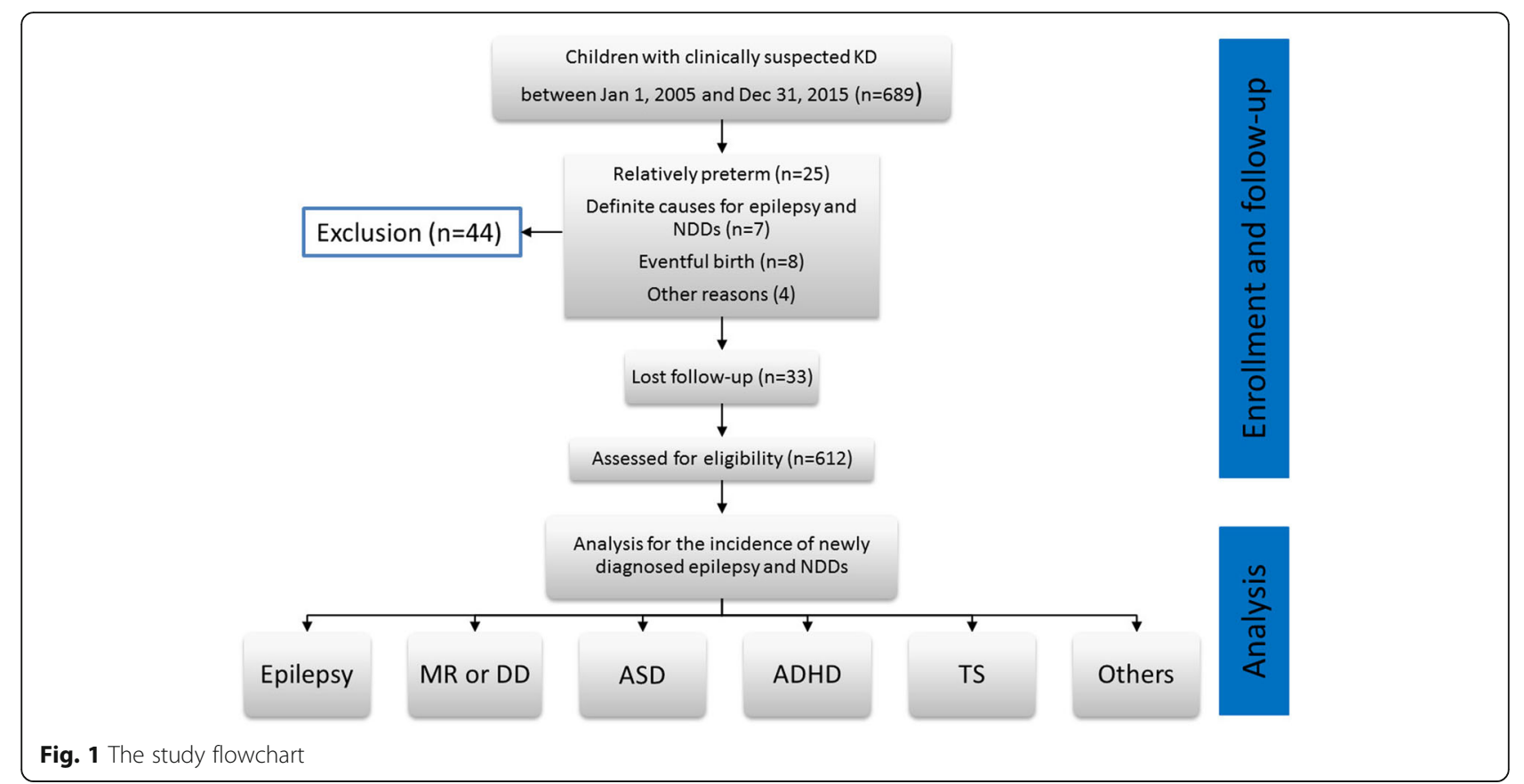

Table 1. Participants' mean age was 1.6 years (standard deviation, 2.4 years). The proportion of boys was higher than that of girls $(64.3 \%$ vs $35.6 \%)$. Positive cardiovascular findings at diagnosis were $48.2 \%$; the proportion of patients who underwent treatment with intravenous immune globulin was $99 \%$.

\section{Neurodevelopmental disabilities associated with KD}

Associated neurodevelopmental disabilities ( $n=103 / 612$, $16.8 \%)$ in the study were classified as epilepsy, ID, ASD,

Table 1 Demographic data of children with KD

\begin{tabular}{ll}
\hline Demographic data & Children with KD $(n=612)(\%)$ \\
\hline Sex & $394(64.3)$ \\
Male & $218(35.6)$ \\
Mean age onset of KD (yrs) (SD) & $1.6 \pm 2.4$ \\
Stratified by age (years) & \\
$0-2$ & $501(81.8)$ \\
$2-5$ & $70(11.4)$ \\
$5-10$ & $32(5.2)$ \\
$>10$ & $9(1.4)$ \\
Cardiovascular findings at diagnosis & \\
Positive & $295(48.2)$ \\
Negative & $317(51.7)$ \\
Treatment with intravenous immune globulin (IVIG; $2 \mathrm{~g} / \mathrm{kg})$ \\
Yes, within 10 days & $538(87.9)$ \\
Yes, over 10 days & $67(10.9)$ \\
No & $7(1.1)$ \\
\hline
\end{tabular}

TS, ADHD, and others (e.g., communication and developmental language disorders). During the follow-up period, few patients developed only one NDD, with the majority being diagnosed with developmental language disorders $(n=18)$, followed by ID $(n=16)$, ADHD $\quad(n=14)$, epilepsy $(n=12)$ and TS $(n=10$; Fig. 2a). Few patients developed two NDDs, with the majority being diagnosed with ADHD + TS $(n=5)$, followed by ADHD + ASD $(n=3)$ and ADHD + developmental language disorders $(n=3)$. Three individual patients developed more than two NDDs, namely epilepsy + ADHD + hearing impairment, ADHD + developmental language disorders + hearing impairment, and ADHD + developmental language disorders + sleep-associated disorders, respectively (Fig. 2b).

\section{Comparison of the prevalence of neurodevelopmental disabilities between children with KD and the general population}

We compared all and individual NDDs between children with $K D$ and the general pediatric population in Taiwan and worldwide (Table 2) [12-54]. Our data revealed that children with KD had higher prevalence rates of any NDD than did the general pediatric population in Taiwan (16.8\% vs $1.3-3 \%$ in publications and $5.89 \%$ in NHIRD), $p<0.05$ ), but this difference has not been significantly observed in other large-scale studies conducted worldwide [12-19]. Similarly, children with KD had a higher prevalence rate of ASD than did the general pediatric population in Taiwan $(1.46 \%$ vs $0.08-0.29 \%$ in publications and $0.41 \%$ in NHIRD, $p<0.05)$, but no significant 


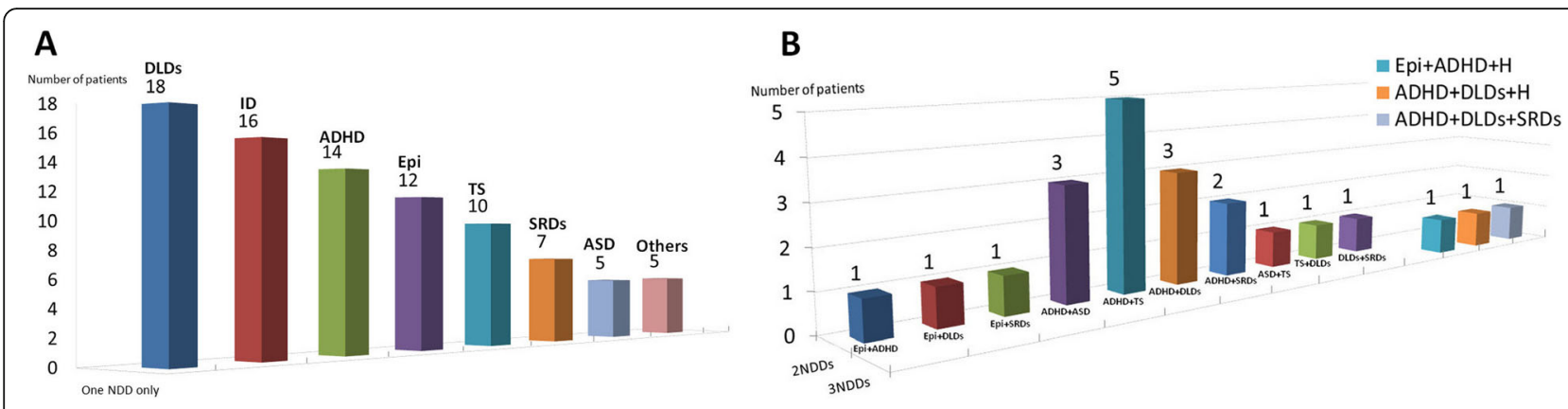

Fig. 2 Heterogeneous neurodevelopmental disabilities distributed in single and combined types among children with KD in the study. a Children with one NDD only ${ }^{\dagger}$ (b) Children with two or more NDDs ${ }^{\ddagger}{ }^{\dagger \ddagger}$ Epi, epilepsy; ID, Intellectual disability; ADHD, Attention deficit hyperactivity disorder; ASD, Autism spectrum disorder; DLDs, Developmental language disorders; $H$, hearing impairment; SRDs, sleep-related disorders; TS, Tourette syndrome.

difference was observed between our findings and those reported in other studies conducted worldwide [38-45]. However, children with KD had higher prevalence rates of epilepsy and TS in both Taiwan and worldwide (epilepsy: $2.61 \%$ in the KD group vs $0.33 \%$ in publication in Taiwan $(0.67 \%$ in NHIRD) and $0.05-0.8 \%$ in worldwide $[p<0.05]$ [24-28]; TS: $2.77 \%$ in the $\mathrm{KD}$ group vs $0.56 \%$ in publication in Taiwan $(0.37 \%$ in NHIRD) and $0.3-1 \%$ in worldwide $[p<0.05]$ [46-50]. Table 3 further compares the possible confounders in children with KD with the development of different neurodevelopmental disabilities. No significant differences were found in terms of whether the children had cardiovascular findings at diagnosis and the timing of IVIG treatment.

\section{Discussion}

The prevalence of NDDs in children ranges from 3 to $18 \%$ worldwide; the prevalence varies among different populations and different study designs [13-19]. Although NDDs in children are common and essentially nonfatal, their treatment is expensive and imposes heavy burden not only on patients but also on family and society. In the present study, we found that $16.8 \%$ of children with KD developed NDDs at follow-up (3-12 years), which was significantly higher than that in the Taiwan population. Their NDDs were highly variable, including developmental language disorders, followed by ADHD, epilepsy, TS, ID, and sleep-associated disorders. Moreover, we found higher incidences of epilepsy and TS in the study group, which were significant in both Taiwan and worldwide. However, a higher prevalence of ASD was found in the study, but this was not significantly different when compared with worldwide data [38-54].

Whether KD results in long-term neurological problems is still controversial, and few studies have explored their relevance. A retrospective study including 65 patients reported an increase in long-term behavior sequelae in children following KD when compared with hospital- and sibling-matched controls [8]. By contrast, another study showed no difference in the incidence of

Table 2 Prevalence of neurodevelopmental conditions for children with KD during the whole year of 2018 versus those in the Taiwan and worldwide

\begin{tabular}{|c|c|c|c|c|c|}
\hline \multirow{3}{*}{$\begin{array}{l}\text { Neurobehavioral } \\
\text { conditions (n) }\end{array}$} & \multirow{3}{*}{$\begin{array}{l}\text { Our } \\
\text { children with KD } \\
(n=612) \\
\text { Prevalence }\end{array}$} & \multicolumn{4}{|l|}{ Controls: } \\
\hline & & \multicolumn{3}{|l|}{ Taiwan population } & \multirow{2}{*}{$\begin{array}{l}\text { Worldwide } \\
\text { Prevalence } \\
\text { (references) }\end{array}$} \\
\hline & & $\begin{array}{l}\text { Prevalence } \\
\text { (references) }\end{array}$ & Research type & $\begin{array}{l}{ }^{\dagger} \text { Prevalence in } 2016 \text { based on NHIRD } \\
\text { of Taiwan }(n=23,699)(\%)\end{array}$ & \\
\hline Any $(102)^{*}$ & $16.8 \%^{*}$ & $1.3-3 \%(12)$ & Meta-analysis & $1397(5.89)$ & $3-18 \%(13-19)$ \\
\hline ID (17) & $2.9 \%$ & $3.25 \%(20)$ & Population-based & $184(0.78)$ & $1-3 \%(21-23)$ \\
\hline Epilepsy $(16)^{* *}$ & $2.61 \% * *$ & $0.33 \%(24)$ & Population-based & $159(0.67)$ & $0.05-0.8 \%(25-28)$ \\
\hline ADHD (31) & $5.05 \%$ & $6.3 \%(29)$ & Population-based & 1110 (4.68) & $2-18 \%(30-37)$ \\
\hline $\operatorname{ASD}(9)^{*}$ & $1.46 \% \%^{*}$ & $0.08-0.29 \%(38,39)$ & Meta-analysis & $98(0.41)$ & $0.2-2.5 \%(40-45)$ \\
\hline $\operatorname{TS}(17)^{* *}$ & $2.77 \%^{* *}$ & $0.56 \%(46)$ & Large clinic-based & $87(0.37)$ & $0.3-1 \%(47-50)$ \\
\hline DLDs (26) & $4.24 \%$ & N/A & N/A & $1446(6.1)$ & $5-10 \%(51-54)$ \\
\hline
\end{tabular}

${ }^{*} p<0.05$ in Taiwan population only

${ }^{* *} p<0.05$ in both Taiwan and worldwide

${ }^{\dagger} \mathrm{ID}$, Intellectual disability; ADHD, Attention deficit hyperactivity disorder; ASD, Autism spectrum disorder; DLDs, Developmental language disorders; TS, Tourette syndrome; NHIRD, National Health Insurance Research Database 
Table 3 Comparison of prevalence of neurodevelopmental conditions between subgroup of children with KD

\begin{tabular}{|c|c|c|c|c|c|c|}
\hline \multicolumn{7}{|l|}{ Children with KD } \\
\hline Demographic data & $\mathrm{CV}^{+}(n=295)(\%)$ & $\mathrm{CV}^{-}(n=317)(\%)$ & $p$-value & IVIG within 10 days $(n=538)(\%)$ & $\begin{array}{l}\text { IVIG over } 10 \text { days } \\
(n=67)(\%)\end{array}$ & $p$-value \\
\hline ID & $7(2.3)$ & $10(3.1)$ & 0.76 & $14(2.6)$ & $3(4.4)$ & 0.68 \\
\hline Epilepsy & $8(2.7)$ & $8(2.5)$ & 0.88 & $14(2.6)$ & $2(2.9)$ & 0.92 \\
\hline ADHD & $12(4.1)$ & $19(6.0)$ & 0.27 & $27(5.0)$ & $4(5.9)$ & 0.90 \\
\hline ASD & $6(2.0)$ & $3(0.9)$ & 0.26 & $8(1.4)$ & $1(1.4)$ & 0.90 \\
\hline TS & $9(3.1)$ & $8(2.5)$ & 0.69 & $15(2.7)$ & $2(2.9)$ & 0.88 \\
\hline DLDs & $12(4.1)$ & $14(4.4)$ & 0.83 & $23(4.2)$ & $3(4.4)$ & 0.87 \\
\hline
\end{tabular}

${ }^{\dagger} \mathrm{CV}^{+}$, Positive cardiovascular findings at diagnosis; $\mathrm{CV}^{-}$, negative cardiovascular findings at diagnosis; IVIG, intravenous immune globulin

${ }^{\ddagger} I D$, Intellectual disability; ADHD, Attention deficit hyperactivity disorder; ASD, Autism spectrum disorder; DLDs, Developmental language disorders; TS,

Tourette syndrome

general physical and psychosocial health in 110 children with KD compared with the general population sample [7]. In Taiwan, a nationwide study indicated that patients with KD may not have an increased risk of ADHD [55]. By contrast, another population-based study in Taiwan showed that ADHD patients had an increased prevalence of various allergic or autoimmune diseases, including asthma, atopic dermatitis, urticaria, ankylosing spondylitis, ulcerative colitis, and autoimmune thyroid disease; however, KD was not included in this study [56]. Kuo et al. [57] investigated the association between KD and autism in Taiwan by using the Taiwan National Health Insurance Research Database and observed no statistical significance between KD and control groups during the 5-year follow-up period. A negative correlation was observed between KD and ID from the analysis of the same database [58].

The correlation between KD and epilepsy and TS is the most noteworthy part of this study. When we conducted a literature review regarding $\mathrm{KD}$ and epilepsy or seizures, we found that only few articles have discussed their relevance. Shimakawa et al. described seizure characteristics in the clinical course of KD. A case report mentioned an infant who developed petechia lesions and seizures due to subdural hemorrhage during the acute stage of KD [59]. Acute encephalopathy and seizures were reported to be the initial presentation of $\mathrm{KD}$ or preceded the classic symptoms of KD [60]. However, all these aforementioned studies were clinical reports and did not mention the long-term risk of epilepsy. Although we could not determine neuropathogenetic changes occurring in the brain after $\mathrm{KD}$ or during the acute stage of KD,our study proposed the correlation between KD and epilepsy through long-term observation. Brain involvement of systemic autoimmune disorders commonly causes seizures as a presenting symptom[61]. Recent studies have shown a trend that many autoimmune disorders, including multiple sclerosis, diabetes mellitus, celiac disease, thyroid disease, systemic lupus erythematosus, antiphospholipid syndrome, rheumatic arthritis,
Behçet's disease and Sjögren syndrome, possibly increase the risk of epilepsy [62]. KD, essentially an autoimmune vasculitis, was indicated in our results to have 8-fold increased risk of epilepsy than the references. This phenomenon echoes recent research that autoimmune disease have been implicated as causative factors of seizures and epilepsy [63, 64]. In addition, when we investigated the association between KD and TS, no associated publication was discovered in PubMed. Thus, the reason for children with KD in this study exhibiting a higher incidence of TS remains unclear. This issue requires further discussion because TS accounts for an important part of NDDs, and KD might pose as a candidate risk factor [65].

Our results partially echoed the hypothesis of previous studies for the negative correlation between $\mathrm{KD}$ and other NDDs, such as KD and ADHD, KD and ID, and $\mathrm{KD}$ and developmental language disorders. To date, the classification of NDDs is complex and is still considered "in progress" [66]. Hence, the more NDDs are discovered with time and the more we understand the role of autoimmunity in NDDs, the more we are interested in the effect of KD on NDDs [67-69]. Therefore, we assume that $K D$, possibly a consequence of immunologic response following a systemic, inflammatory illness [70, 71], should also be regarded as a potential risk factor for NDDs. However, future studies may use larger study samples and more in-depth study designs.

This study has some limitations. First, some confounding factors may have affected the results, such as mothers' medical condition during pregnancy, socioeconomic status, other pharmacological treatment of children with $\mathrm{KD}$, different severities of $\mathrm{KD}$, and other environmental factors. Second, we did not include a control group for our children with KD, the methodology used in other comparative studies was not the same as that used in the present study, and the definition of NDDs used in other comparative studies was not the same as that used in the present study (e.g., for NDDs, other studies used "prevalence, whereas we used 
"incidence"); in addition, inconsistent observation periods between other studies and our study may have affected final results. Third, because NDDs are a spectrum of conditions with heterogeneity in disease types, geographic incidence, and population incidence, we could not analyze all NDD types and different populations because of the restrictions of study design. Furthermore, additional research focusing on neuroimaging, genetic susceptibility, or proinflammatory cytokines and other environmental exposures may identify potential mechanisms underlying NDDs in children with KD [7].

\section{Conclusions}

The results of this study revealed a higher prevalence rate of NDDs in children with KD in Taiwan. However, these NDDs could be heterogeneous. Among them, children with KD have a higher prevalence of epilepsy and TS remarkably, but no significance difference was observed among ID, ADHD, and developmental language disorders. Children diagnosed with KD should be followed up because they have a higher risk of heterogeneous NDDs. More studies enrolling larger sample sizes and more indepth study designs containing different cofounders are necessary in the future.

\section{Abbreviations}

ADHD: Attention deficit hyperactivity disorder; ASD: Autism spectrum disorders; ID: Intellectual disability; KD: Kawasaki disease;

NDDs: Neurodevelopmental disorders; TS: Tourette syndrome

\section{Acknowledgements}

We would like to thank the Genetic Medicine Laboratory of China Medical University Hospital, Ministry of Science and Technology of ROC (MOST 1072314-B-039-003) and China Medical University Hospital Medical Research Department (DMR-108-199) for giving support and assistance to this work.

\section{Authors' contributions}

SYH collected and analyzed the data and prepared the draft. CHL and WDL participated in the design of the study and wrote the manuscript. ICL and ICC compiled the statistics of this study and participated in the editing and revising the tables. All authors read and approved the final manuscript.

\section{Funding}

Not applicable

Availability of data and materials

Competing interest

The authors declare that they have no competing interests.

\section{Ethics approval and consent to participate}

After a full description of the study, written informed consent of participation was obtained from the legal guardians. The study protocol was approved by the Ethics Review Board of the China Medical University ethics committee (Approval \# CMUH108-REC1-023 and CMUH107-REC2-152).

\section{Consent for publication}

Not applicable

\section{Author details}

'Division of Pediatrics Pulmonology, China Medical Univeristy Children's Hospital, Taichung, Taiwan. ${ }^{2}$ Department of Biomedical Imaging and Radiological Science, College of Medicine, China Medical University,
Taichung, Taiwan. ${ }^{3}$ Department of Medical Research, China Medical University Hospital, Taichung, Taiwan. ${ }^{4}$ Division of Pediatrics Neurology, China Medical Univeristy Children's Hospital, Taichung, Taiwan. ${ }^{5}$ Graduate Institute of Integrated Medicine, College of Chinese Medicine, China Medical University, Taichung, Taiwan. ${ }^{6}$ Department of Pediatrics, Chung Shan Medical University Hospital and Institute of Medicine, School of Medicine, Chung Shan Medical University, Taichung, Taiwan.

Received: 20 May 2019 Accepted: 14 October 2019

Published online: 04 November 2019

\section{References}

1. Burns JC, Glodé MP. Kawasaki syndrome. Lancet. 2004;364:533-44.

2. Orenstein JM, Shulman ST, Fox LM, Baker SC, Takahashi M, Bhatti TR, et al. Three linked vasculopathic processes characterize Kawasaki disease: a light and transmission electron microscopic study. PLoS One. 2012;7:e38998.

3. Amano S, Hazama F, Hamashima Y. Pathology of Kawasaki disease: II. Distribution and incidence of the vascular lesions. Jpn Circ J. 1979;43:741-8.

4. Tomita S, Chung K, Mas M, Gidding S, Shulman ST. Peripheral gangrene associated with Kawasaki disease. Clin Infect Dis. 1992;14:121-6.

5. Veiga PA, Pieroni D, Baier W, Feld LG. Association of Kawasaki disease and interstitial nephritis. Pediatr Nephrol. 1992;6:421-3.

6. Mele T, Evans M. Intestinal obstruction as a complication of Kawasaki disease. J Pediatr Surg. 1996;31:985-6.

7. Baker AL, Gauvreau K, Newburger JW, Sundel RP, Fulton DR, Jenkins KJ. Physical and psychosocial health in children who have had Kawasaki disease. Pediatrics. 2003;111:579-83.

8. Carlton-Conway D, Ahluwalia R, Henry L, Michie C, Wood L, Tulloh R. Behaviour sequelae following acute Kawasaki disease. BMC Pediatr. 2005:5:14.

9. Magalhães CM, Magalhães Alves NR, Oliveira KM, Silva IM, Gandolfi L, Pratesi R. Sensorineural hearing loss: an underdiagnosed complication of Kawasaki disease. J Clin Rheumatol. 2010;16:322-5.

10. Ayusawa M, Sonobe T, Uemura S, Ogawa S, Nakamura Y, Kiyosawa N, et al. Revision of diagnostic guidelines for Kawasaki disease (the 5th revised edition). Pediatr Int. 2005;47:232-4.

11. Definitions and classification of tic disorders. The Tourette Syndrome Classification Study Group. Arch Neurol. 1993;50:1013-6.

12. Wang KY. Updated findings on neurodevelopmental disorders in Taiwan: impact of the institutionalized national healthcare system on prevalence and health outcomes. Curr Opin Psychiatry. 2016;29:144-8.

13. Arora NK, Nair MKC, Gulati S, Deshmukh V, Mohapatra A, Mishra D, et al. Neurodevelopmental disorders in children aged 2-9 years: population-based burden estimates across five regions in India. PLoS Med. 2018;15:e1002615.

14. Emerson E. Deprivation, ethnicity and the prevalence of intellectual and developmental disabilities. J Epidemiol Community Health. 2012;66:218-24.

15. Taylor E. Developing ADHD. J Child Psychol Psychiatry. 2009;50:126-32.

16. Johnson S, Fawke J, Hennessy E, Rowell V, Thomas S, Wolke D, et al. Neurodevelopmental disability through 11 years of age in children born before 26 weeks of gestation. Pediatrics. 2009:124:e249-57.

17. Zauche LH, Darcy Mahoney AE, Higgins MK. Predictors of co-occurring neurodevelopmental disabilities in children with autism Spectrum disorders. J Pediatr Nurs. 2017;35:113-9.

18. Hansen BH, Oerbeck B, Skirbekk B, Petrovski BÉ, Kristensen H. Neurodevelopmental disorders: prevalence and comorbidity in children referred to mental health services. Nord J Psychiatry. 2018;72:285-91.

19. Tatishvili N, Gabunia M, Laliani N, Tatishvili S. Epidemiology of neurodevelopmental disorders in 2 years old Georgian children. Pilot study - population based prospective study in a randomly chosen sample. Eur J Paediatr Neurol. 2010;14:247-52.

20. Kuo HT, Muo CH, Chang YT, Lin CK. Change in prevalence status for children with developmental delay in Taiwan: a nationwide populationbased retrospective study. Neuropsychiatr Dis Treat. 2015;11:1541-7.

21. Shevell M, Ashwal S, Donley D, Flint J, Gingold M, Hirtz D, et al. Practice parameter: evaluation of the child with global developmental delay: report of the quality standards Subcommittee of the American Academy of neurology and the practice Committee of the Child Neurology Society. Neurology. 2003;60:367-80.

22. Maulik PK, Mascarenhas MN, Mathers CD, Dua T, Saxena S. Prevalence of intellectual disability: a meta-analysis of population-based studies. Res Dev Disabil. 2011;32:419-36. 
23. Moeschler JB. Shevell M; American Academy of Pediatrics Committee on genetics. Clinical genetic evaluation of the child with mental retardation or developmental delays. Pediatrics. 2006;117:2304-16.

24. Chiang KL, Cheng CY. Prevalence and neuro-psychiatric comorbidities of pediatric epilepsy in Taiwan: a national population-based study. Epilepsy Res. 2014;108:1451-60.

25. Hauser WA, Annegers JF, Kurland LT. Prevalence of epilepsy in Rochester, Minnesota: 1940-1980. Epilepsia. 1991;32:429-45.

26. Oka E, Ohtsuka Y, Yoshinaga H, Murakami N, Kobayashi K, Ogino T. Prevalence of childhood epilepsy and distribution of epileptic syndromes: a population-based survey in Okayama, Japan. Epilepsia. 2006;47:626-30.

27. Russ SA, Larson K, Halfon N. A national profile of childhood epilepsy and seizure disorder. Pediatrics. 2012;129:256-64.

28. Aaberg KM, Gunnes N, Bakken IJ, Lund Søraas C, Berntsen A, Magnus P, et al. Incidence and Prevalence of Childhood Epilepsy: A Nationwide Cohort Study. Pediatrics. 2017;139:e20163908.

29. Liu A, Xu Y, Yan Q, Tong L. The prevalence of attention deficit/hyperactivity disorder among Chinese children and adolescents. Sci Rep. 2018;8:11169.

30. Subcommittee on Attention-Deficit/Hyperactivity Disorder; Steering Committee on Quality Improvement and Management, Wolraich M, Brown L, Brown RT, DuPaul G, et al. ADHD: clinical practice guideline for the diagnosis, evaluation, and treatment of attention-deficit/ hyperactivity disorder in children and adolescents. Pediatrics. 2011;128: 1007-22.

31. Sharma A, Couture J. A review of the pathophysiology, etiology, and treatment of attention-deficit hyperactivity disorder (ADHD). Ann Pharmacother. 2014:48:209-25.

32. Barbaresi W, Katusic S, Colligan R, Weaver A, Pankratz V, Mrazek D, et al. How common is attention-deficit/hyperactivity disorder? Towards resolution of the controversy: results from a population-based study. Acta Paediatr Suppl. 2004;93:55-9.

33. Froehlich TE, Lanphear BP, Epstein JN, Barbaresi WJ, Katusic SK, Kahn RS. Prevalence, recognition, and treatment of attention-deficit/hyperactivity disorder in a national sample of US children. Arch Pediatr Adolesc Med. 2007:161:857-64.

34. Pliszka S. AACAP work group on quality issues. Practice parameter for the assessment and treatment of children and adolescents with attentiondeficit/hyperactivity disorder. J Am Acad Child Adolesc Psychiatry. 2007;46: 894-921.

35. Merikangas KR, He JP, Brody D, Fisher PW, Bourdon K, Koretz DS. Prevalence and treatment of mental disorders among US children in the 2001-2004 NHANES. Pediatrics. 2010;125:75-81.

36. Boyle CA, Boulet S, Schieve LA, Cohen RA, Blumberg SJ, Yeargin-Allsopp M, et al. Trends in the prevalence of developmental disabilities in US children, 1997-2008. Pediatrics. 2011;127:1034-42.

37. Danielson ML, Bitsko RH, Ghandour RM, Holbrook JR, Kogan MD, Blumberg SJ. Prevalence of parent-reported ADHD diagnosis and associated treatment among U.S. children and adolescents, 2016. J Clin Child Adolesc Psychol. 2018;47:199-212.

38. Chien IC, Lin CH, Chou YJ, Chou P. Prevalence and incidence of autism spectrum disorders among national health insurance enrollees in Taiwan from 1996 to 2005. J Child Neurol. 2011;26:830-4.

39. Sun X, Allison C, Matthews FE, Sharp SJ, Auyeung B, Baron-Cohen S, et al. Prevalence of autism in mainland China, Hong Kong and Taiwan: a systematic review and meta-analysis. Mol Autism. 2013;4:7.

40. Baxter AJ, Brugha TS, Erskine HE, Scheurer RW, Vos T, Scott JG. The epidemiology and global burden of autism spectrum disorders. Psychol Med. 2015;45:601-13.

41. Developmental Disabilities Monitoring Network Surveillance Year 2010 Principal Investigators; Centers for Disease Control and Prevention (CDC). Prevalence of autism spectrum disorder among children aged 8 years - autism and developmental disabilities monitoring network, 11 sites, United States, 2010. MMWR Surveill Summ. 2014;63:1-21.

42. Baird G, Simonoff E, Pickles A, Chandler S, Loucas T, Meldrum D, et al. Prevalence of disorders of the autism spectrum in a population cohort of children in South Thames: the special needs and autism project (SNAP). Lancet. 2006;368:210-5.

43. Webb E, Morey J, Thompsen W, Butler C, Barber M, Fraser Wl. Prevalence of autistic spectrum disorder in children attending mainstream schools in a welsh education authority. Dev Med Child Neurol. 2003;45:377-84.
44. Xu G, Strathearn L, Liu B, Bao W. Prevalence of autism Spectrum disorder among US children and adolescents, 2014-2016. JAMA. 2018;319:81-82. Schendel DE, Thorsteinsson E. cumulative incidence of autism into adulthood for birth cohorts in Denmark, 1980-2012. JAMA. 2018;320:1811-3.

45. Wang HS, Kuo MF. Tourette's syndrome in Taiwan: an epidemiological study of tic disorders in an elementary school at Taipei County. Brain and Development. 2003;25(Suppl 1):S29-31.

46. Freeman RD, Fast DK, Burd L, Kerbeshian J, Robertson MM, Sandor P. An international perspective on Tourette syndrome: selected findings from 3,500 individuals in 22 countries. Dev Med Child Neurol. 2000;42:436-47.

47. Centers for Disease Control and Prevention (CDC). Prevalence of diagnosed Tourette syndrome in persons aged 6-17 years - United States, 2007. MMWR Morb Mortal Wkly Rep. 2009;58:581-5.

48. Knight T, Steeves T, Day L, Lowerison M, Jette N, Pringsheim T. Prevalence of tic disorders: a systematic review and meta-analysis. Pediatr Neurol. 2012; 47:77-90.

49. Robertson MM. The prevalence and epidemiology of Gilles de la Tourette syndrome. Part 1: the epidemiological and prevalence studies. J Psychosom Res. 2008;65:461-72

50. Stothard SE, Snowling MJ, Bishop DV, Chipchase BB. Kaplan CA languageimpaired preschoolers: a follow-up into adolescence. J Speech Lang Hear Res. 1998;41:407-18.

51. Johnson CJ, Beitchman JH, Young A, Escobar M, Atkinson L, Wilson B, et al. Fourteen-year follow-up of children with and without speech/language impairments: speech/language stability and outcomes. J Speech Lang Hear Res. 1992:42:744-60

52. Aram DM, Ekelman BL, Nation JE. Preschoolers with language disorders: 10 years later. J Speech Hear Res. 1984;27:232-44.

53. Catts HW, Fey ME, Tomblin JB, Zhang X. A longitudinal investigation of reading outcomes in children with language impairments. J Speech Lang Hear Res. 2002:45:1142-57.

54. Kuo HC, Chang WC, Wang L, Li SC, Chang WP. Association of Attention deficit hyperactivity disorder and Kawasaki disease: a nationwide population-based cohort study. Epidemiol Psychiatr Sci. 2016;25:573-80.

55. Chen MH, Su TP, Chen YS, Hsu JW, Huang KL, Chang WH, et al. Comorbidity of allergic and autoimmune diseases among patients with ADHD. J Atten Disord. 2017;21:219-27.

56. Kuo HC, Wu CM, Chang WP, Kuo CN, Yeter D, Lin CY, et al. Association between Kawasaki disease and autism: a population-based study in Taiwan. Int J Environ Res Public Health. 2014;11:3705-16.

57. Wang LJ, Kuo HC. Cognitive development after Kawasaki disease - clinical study and validation using a Nationwide population-based cohort. Circ J. 2018;82:517-23.

58. Ho CL, Jan SL, Fu YC, Lin MC, Lin SJ. Petechia and seizure in an infant with acute Kawasaki disease. Clin Pediatr (Phila). 2010;49:997-9.

59. Tabarki B, Mahdhaoui A, Selmi H, Yacoub M, Essoussi AS. Kawasaki disease with predominant central nervous system involvement. Pediatr Neurol. 2001;25:239-41.

60. Clarke RA, Lee S, Eapen V. Pathogenetic model for Tourette syndrome delineates overlap with related neurodevelopmental disorders including autism. Transl Psychiatry. 2012;2:e158.

61. Devinsky O, Schein A, Najjar S. Epilepsy associated with systemic autoimmune disorders. Epilepsy Curr. 2013:13:62-8.

62. Vincent A, Crino PB. Systemic and neurologic autoimmune disorders associated with seizures or epilepsy. Epilepsia. 2011;52(Suppl 3):12-7.

63. Valencia I. Epilepsy in systemic autoimmune disorders. Semin Pediatr Neurol. 2014;21:226-31.

64. Dutra LA, Braga-Neto P, Pedroso JL, Guedes Bde V, de Souza LT, Gonçalves $\mathrm{CR}$, et al. Epilepsy and Behçet's disease: cortical and hippocampal involvement in Brazilian patients. J Neurol Sci. 2011;309:1-4.

65. Posar A, Visconti P. Neurodevelopmental disorders between past and future J Pediatr Neurosci. 2017;12:301-2

66. Swedo SE. Genetics of childhood disorders: XXXIII. Autoimmunity, part 6: poststreptococcal autoimmunity. J Am Acad Child Adolesc Psychiatry. 2001; 40:1479-82

67. Pavone P, Bianchini R, Parano E, Incorpora G, Rizzo R, Mazzone L, et al. Antibrain antibodies in PANDAS versus uncomplicated streptococcal infection. Pediatr Neurol. 2004;30:107-10.

68. Homberg JR, Kyzar EJ, Scattoni ML, Norton WH, Pittman J, Gaikwad S, et al. Genetic and environmental modulation of neurodevelopmental disorders: translational insights from labs to beds. Brain Res Bull. 2016;125:79-91. 
69. Brown TJ, Crawford SE, Cornwall ML, Garcia F, Shulman ST, Rowley AH. CD8 T lymphocytes and macrophages infiltrate coronary artery aneurysms in acute Kawasaki disease. J Infect Dis. 2001;184:940-3.

70. Naoe S, Takahashi K, Masuda H, Tanaka N. Kawasaki disease. With particular emphasis on arterial lesions. Acta Pathol Jpn. 1991;41:785-97.

71. Takahashi K, Oharaseki T, Yokouchi Y. Pathogenesis of Kawasaki disease. Clin Exp Immunol. 2011;164(Suppl 1):20-2.

\section{Publisher's Note}

Springer Nature remains neutral with regard to jurisdictional claims in published maps and institutional affiliations.

Ready to submit your research? Choose BMC and benefit from:

- fast, convenient online submission

- thorough peer review by experienced researchers in your field

- rapid publication on acceptance

- support for research data, including large and complex data types

- gold Open Access which fosters wider collaboration and increased citations

- maximum visibility for your research: over $100 \mathrm{M}$ website views per year

At $\mathrm{BMC}$, research is always in progress.

Learn more biomedcentral.com/submissions 